\title{
Late Presentation of Aortopulmonary Window with Tetralogy of Fallot: Report of a Very Rare Case
}

\author{
Muhammad Ishtiaque Sayeed Al-Manzo ${ }^{a} \quad$ Prodip Kumar Biswas $^{\text {a }} \quad$ M.A.K. Azad ${ }^{a}$ \\ Eliyas Patwary $^{\mathrm{a}}$ Jesmin Hossain ${ }^{\mathrm{b}}$ Abul Kalam Shamsuddin ${ }^{\mathrm{a}}$ \\ aDepartment of Pediatric Cardiac Surgery, National Heart Foundation Hospital \& Research Institute, Dhaka, Bangladesh; \\ ${ }^{b}$ Department of Pediatric Cardiology, National Heart Foundation Hospital \& Research Institute, Dhaka, Bangladesh
}

\section{Keywords}

TOF with A-P window · Aortopulmonary window · Late presentation of AP window

\begin{abstract}
Aortopulmonary window (APW) itself is a rare congenital cardiac malformation and its association with Tetralogy of Fallot (TOF) makes it more uncommon. We report a case of APW with TOF who presented at 4-year 10 months of age. As the boy was still in operable state, after thorough preoperative evaluation successful surgical repair was done.
\end{abstract}

\footnotetext{
(c) 2021 The Author(s).

Published by S. Karger AG, Basel
}

\section{Introduction}

Aortopulmonary window (APW) is a rare truncal anomaly occurring in $0.2-0.6 \%$ of all patients with congenital cardiac disease [1]. Almost half of the patients have coexisting other cardiac lesions like patent ductus arteriosus, right aortic arch, and patent foramen ovale, ventricular septal defect, interrupted aortic arch, transposition of the great arteries, tetralogy of Fallot (TOF), and coronary artery anomalies [2]. Its association with TOF is very rare with only a few cases reported so far [3-5]. So the natural history of patients with this combination is not well described. Unlike this case, most of the reported cases were diagnosed and treated in their infancy as these patients are prone to developed irreversible pulmonary vascular changes at an early age [6].

\section{Case Report}

A 4-year 10-months old otherwise asymptomatic boy visited our outpatient department to evaluate a systolic murmur in the left sternal border detected by his local physician. He had an uneventful infancy with no history of breathing difficulty, repeated chest infection, or cyanosis. Clinical examination revealed a grade 3/6 ejection systolic murmur in the left sternal border, and oxygen saturation of $97 \%$ in room air. Electrocardiogram showed biventricular hypertrophy and chest radiography demonstrated enlarged cardiac shadow, right ventricular type apex, and bilateral increased pulmonary vascular markings. Transthoracic echocardiography revealed TOF, severe infundibular and valvular pulmonary stenosis with an APW. Computed tomography angiogram showed an APW of $21.9 \mathrm{~mm}$ diameter between mid-part of ascending aorta and main pulmonary artery along with TOF. Cardiac catheterization (Fig. 1) revealed significant step-up of $\mathrm{O}_{2}$ from right ventricle to pulmonary artery level, mean pulmonary artery karger@karger.com www.karger.com/dmj

Karger $\stackrel{\text { ' }}{=}$
(C) 2021 The Author(s)

Published by S. Karger AG, Basel

This is an Open Access article licensed under the Creative Common Attribution-NonCommercial-4.0 International License (CC BY-NC) (http://www.karger.com/Services/OpenAccessLicense), applicable to the online version of the article only. Usage and distribution for commercial purposes requires written permission.
Correspondence to:

Muhammad Ishtiaque Sayeed Al-Manzo, ishti1432@gmail.com 


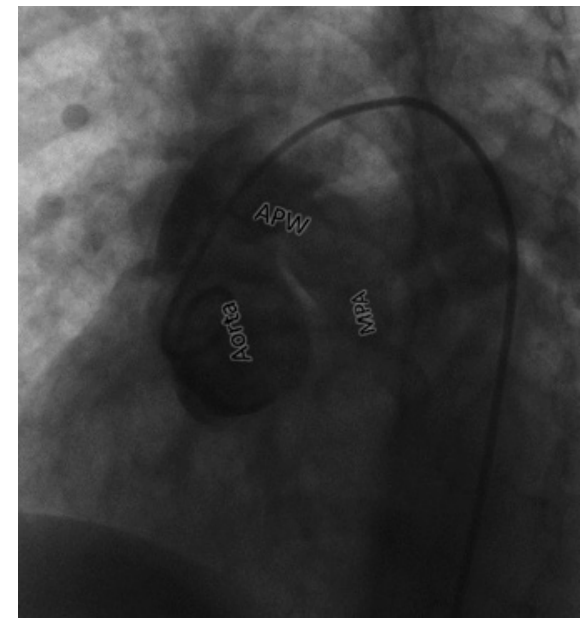

Fig. 1. Cineangiogram shows a large APW with MPA stenosis. APW, Aortopulmonary window; MPA, main pulmonary artery.

pressure was $55 \mathrm{~mm}$ of $\mathrm{Hg}$, pulmonary to systemic blood flow $\left(Q_{\mathrm{p}}\right.$ : $Q_{\mathrm{s}}$ ) was 2.67, indexed pulmonary vascular resistance (PVRI) was 4.94 Wood units $/ \mathrm{m}^{2}$ and pulmonary to systemic vascular resistance ratio (PVR: SVR) was 0.27 .

Surgical correction was planned as he was found to be operable even at this age both clinically and thorough investigations. After median sternotomy both left and right pulmonary artery dissected free and looped. Aorta was cannulated well above the APW. Cardiopulmonary bypass was established with aortic and bicaval cannulation. Aortic cross-clamp was applied and heart was arrested with Del Nido cardioplegia after snugging both branch pulmonary arteries. Vertical aortotomy was done (Fig. 2) and APW was closed using $0.4 \mathrm{~mm}$ polytetrafluoroethylene patch, especially caring coronary ostia, aortic valve, and origin of right pulmonary artery. Dacron patch repair of ventricular septal defect, right ventricular muscle band resection, pulmonary valve reconstruction with $0.1 \mathrm{~m}$ polytetrafluoroethylene, transannular patch augmentation with pericardium and fenestration in intra-atrial septum was done for repairing rest of the defects.

Measures were taken to prevent pulmonary hypertensive crisis during both preoperative and postoperative period. But pulmonary vasodilators had to be withheld as he developed raised hepatic enzymes. Only oxygen inhalation was continued till liver function became normal. He was shifted toward from ICU on 12th POD and discharged home on 17th POD. He is on regular followup for more than 2 years. Pulmonary vasodilator was continued up to first 3 months along with diuretics. His pulmonary pressure gradually reduced to normal level which was evident by serial echocardiography and now he is maintaining a healthy life.

\section{Discussion}

APW is a rare malformation results from an abnormal communication between 2 great arteries distal to their seminular valve. This incomplete formation of conotrun-

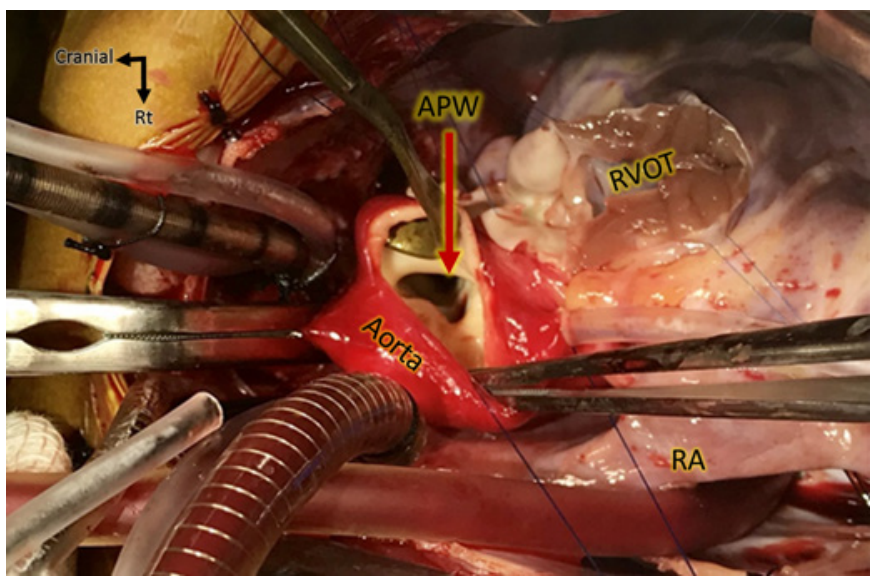

Fig. 2. Intraoperative photograph showing the APW. RA, Rt atrium; RVOT, Rt ventricular outflow tract; APW, Aortopulmonary window.

cal septum may produce a wide spectrum of morphologic variation which is classified into different ways. As the hemodynamic consequence of a continuous shunting of blood from aorta to pulmonary artery, patients usually become symptomatic in the first month of life and the signs and symptoms show rapid progression [7].

Most APWs are nonrestrictive. Hence, if closure of the defect is not done at an early age, beyond infancy either patients do not survive or develop irreversible pulmonary vascular obstructive disease [8]. In contrast to the natural history, late presentation of APW due to delayed diagnosis is not uncommon in third world countries [9]. But its association with TOF is noteworthy.

Assessment of operability is the most significant issue after diagnosis, especially in patients with late presentation. Presence of predominantly left-to-right shunt across the APW can be predicted clinically by signs of increased pulmonary blood flow like presence of cardiomegaly, left ventricular third sound (LVS3) and flow murmur across the mitral valve and lack of arterial desaturation at rest and exercise. Chest X-ray, electrocardiogram, and echocardiogram also contribute to assessing pulmonary to systemic blood flow $\left(Q_{p} / Q_{s}\right)[6]$. For this boy, the presence of TOF along with APW created a tangle in taking a straightforward decision regarding surgical correction. Ultimately cardiac catheterization confirmed favorable parameters regarding his operability in spite of his large window shunting blood to lung for more than 4 years.

Surgical repair techniques for AP window have evolved from off-pump ligation, division, and suturing to on-by- 
pass transpulmonary artery, transaortic direct or patch closure, or anterior sandwich patch closure [10]. As the trans-aortic repair using CPB allows accurate visualization of coronaries arteries, aortic valve, and right pulmonary artery origin this technique was preferred for this patient.

A fairly identical anatomical and physiological situation is often surgically created in case of TOF patients undergoing palliation with a shunt between aorta and main pulmonary artery. An oversize shunt might lead to a significant increase in pulmonary blood flow causing pulmonary hypertension, eventually leading toward pulmonary vascular occlusive disease [11]. So these patients must undergo a subsequent intervention without much delay.

\section{Conclusion}

Presence of a systemic-pulmonary shunt through APW can mask the effects of pulmonary stenosis and patient might remain acyanotic, as happened with this case. But assessment of pulmonary vascular disease in a late presentation of APW with TOF is a bit challenging job. With adequate preoperative evaluation, surgical correction can ensure a cure for the patient.

\section{Statement of Ethics}

Father of this patient has given written informed consent to publish this case (including publication of images).

\section{Conflict of Interest Statement}

The authors have no conflicts of interest to declare.

\section{Funding Sources} tion.

No sponsors/funding was there for this case report prepara-

\section{Author Contributions}

M.I.S.A.M. actively participated in writing this article. P.K.B. actively participated in writing process of this article. M.A.K.A. actively participated in writing process of this article. E.P. critically reviewed the article. J.H. critically reviewed the article. A.K.S. the article was prepared according to his guidance.

\section{Data Availability Statement}

All data generated or analyzed during this case report are included in this article. Further enquiries can be directed to the corresponding author.

\section{References}

1 Kutsche LM, Van Mierop LH. Anatomy and pathogenesis of aorticopulmonary septal defect. Am J Cardiol. 1987;59:443-7.

2 Bhan A, Gupta M, Abraham S, Sharma R, Kothari SS, Juneja R. Surgical experience of aortopulmonary window repair in infants. Interact Cardiovasc Thorac Surg. 2007;6:200-3.

3 Alborino D, Guccione P, Di Donato R, Marino B. Aortopulmonary window coexisting with tetralogy of fallot. J Cardiovasc Surg. 2001;42:197-9.

4 Malec E, Brzegowy P, Mroczek T. Surgical treatment of aortopulmonary window with tetralogy of Fallot. Scand Cardiovasc J. 2001; 35:159-60.
5 Bhalgat P, Kulkarni D, Lovhale P. Tetralogy of Fallot and aortopulmonary window: diagnosis and management. IHJ Cardiovasc Case Rep. 2020;4(2):77-9.

6 Talwar S, Siddharth B, Gupta SK, Choudhary SK, Kothari SS, Juneja R, et al. Aortopulmonary window: results of repair beyond infancy. Interact Cardiovasc Thorac Surg. 2017;25: $740-4$.

7 Kose M, Ucar S, Emet S, Akpinar TS, Yalin K. A case of aortopulmonary window: asymptomatic until the first pregnancy. Case Rep Cardiol. 2015;2015:935253.

8 McElhinney DB, Reddy VM, Tworetzky W, Silverman NH, Hanley FL. Early and late results after repair of aortopulmonary septal defect and associated anomalies in infants. Am J Cardiol. 1998;81:195-201.
9 World Health Organization. Health manpower requirements for the achievement of health for all by the year 2000 through primary health care. Report of a WHO Expert Committee. World Health Organ Tech Rep Ser. 1985;717:7-92.

10 Backer CL, Mavroudis C. Surgical management of aortopulmonary window: a 40 -year experience. Eur J Cardiothorac Surg. 2002;21: 773-9.

11 Presbitero P, D'Antonio P, Brusca A, Morea M. Prognosis of Ffallot's tetralogy after palliative operations: 10-25 year follow-up. Pediatr Cardiol. 1983;4:175-82. 